\title{
Therapies Based on Nanoparticles for Eye Drug Delivery
}

Alejandra Meza-Rios $\cdot$ Jose Navarro-Partida $\cdot$ Juan Armendariz-Borunda

Arturo Santos

Received: April 7, 2020 / Published online: May 7, 2020

(C) The Author(s)

\section{ABSTRACT}

Eye drug delivery, particularly to the retina, is a technical hurdle that needs to be solved and represents an ongoing current important medical field. Posterior segment eye diseases are a major cause of visual impairment worldwide. Age-related macular degeneration, glaucoma, and diabetic retinopathy are the major causes of blindness. To achieve efficient drug delivery and drug retention time in the posterior segment of the eye, novel delivery systems based on nanoparticles have been developed in the last few years. Nowadays, liposomes represent the most utilized nanoparticles for eye drug delivery and, recently, a broad spectrum of diverse nanoparticles continue to emerge with

Digital features To view digital features for this article go to https://doi.org/10.6084/m9.figshare.12199811.

A. Meza-Rios · J. Navarro-Partida · J. ArmendarizBorunda $\cdot$ A. Santos $(\bowtie)$

Tecnologico de Monterrey, Escuela de Medicina y Ciencias de la Salud, Campus Guadalajara, Zapopan, Jalisco, Mexico

e-mail: arturo.santos@tec.mx

J. Armendariz-Borunda

Institute of Molecular Biology in Medicine and Gene

Therapy, CUCS, University of Guadalajara,

Guadalajara, Jalisco, Mexico

\section{A. Santos}

Centro de Retina Medica y Quirurgica, S.C., Centro

Medico Puerta de Hierro, Zapopan, Mexico special characteristics representing ideal candidates for eye drug delivery.

Keywords: Biotechnology; Eye diseases; Liposomes; Nanoparticles; Posterior segment eye

\section{Key Summary Points}

To date, most common ophthalmic drugs are administered topically in the form of eye drops into the corneal surface.

Topical drugs suffer from low bioavailability.

Nanoparticles increased the solubility of hydrophobic drug, provided sustained drug release with reduced toxicity and improved efficacy, prolonged drug retention time, and enhancement of drug penetration through ocular barriers.

Liposomes are the first nano drug delivery systems that have been successfully translated into real-time clinical applications. 


\section{INTRODUCTION}

Posterior segment eye diseases are a major cause of visual impairment worldwide. Age-related macular degeneration, glaucoma, and diabetic retinopathy, including diabetic macular edema, are the major causes of blindness from the posterior segment; together with uncorrected refractive error and cataract [1, 2]. Macular edema is the abnormal presence of fluid inside the retinal layers of the macula, as a result of breakdown of the blood-retinal barrier, damage to tight junctions between endothelial cells, and secretion into the vitreous of vasopermeability factors such as vascular endothelial growth factor (VEGF) [3]. Macular edema is the major form of ocular condition associated with retinopathy in diabetic patients. Therapeutic options for macular edema include photocoagulation and intravitreal (IVT) injections of corticosteroids or anti-VEGF molecules and in some cases vitrectomy surgery [4].

It is important to note that the standard therapy for age-related macular degeneration and diabetic macular edema is monthly IVT injection of anti-VEGF agents. Because of ocular barriers, ophthalmic and systemic drugs barely get into the posterior segment of the eye. Therefore, IVT is the most used pathway to deliver drugs to the posterior segment. IVT injection is not exempted from potential severe ocular complications including inflammation, vitreous hemorrhage, retinal detachment, and endophthalmitis [5-8]. Also, IVT requires specialized human resources and special infrastructure (taking into account the type of air system of the procedure room to avoid endophthalmitis) to apply it and therefore it is expensive $[8,9]$. On the other hand, in the very old people (at least 90 years of age) a lack of treatment adherence has been observed mainly because the burden of traditional treatment is high [10]. Novel therapeutic strategies have been pursued in the field of ocular drug delivery to increase patient compliance, to reduce the hazards of IVT injection, and, finally, to improve outcomes.

In this review article we describe the recent research results of eye drug delivery nanosystems, focusing on the posterior segment of the eyeball. This article is based on previously conducted studies and does not contain any studies with human participants or animals performed by any of the authors.

\section{POSTERIOR SEGMENT OF THE EYEBALL}

The eye is a small and complex organ that is separated from the rest of the body by different biological barriers [11]. The eyeball consists of an anterior segment and a posterior segment. The posterior segment represents the major ocular structure; it is composed of vitreous humor, sclera, macula, choroid, retina, and optic nerve (Fig. 1) [12, 13].

The retina is a complex ocular structure that converts wavelengths of light into neuronal signals that become perceived visual images. In the retina, five types of neuron-photoreceptors, bipolar cells, retinal ganglion cells, horizontal cells, and amacrine cells-are wired together to form one of nature's most complex circuit boards. When light hits the retina, it stimulates photoreceptors, creating an electrical signal that is conveyed through other neurons of the retina to the optic nerve, and then into the brain [14]. The macula comprises a specialized section of the neural retina, which is present in humans and in non-human primates only. It is integrated by numerous layers of retinal ganglion cells (with a single layer of ganglion cells in the extramacular retina), and represent the region from the temporal margin of the optic nerve head to the center of the macula. In the superior-inferior plane, the macula extends between the two major temporal retinal vascular arcades. It is not clear why the macula is susceptible to large types of disorders, e.g., the macular degenerations, or to edema in a large variety of diseases [15].

The static natural barriers in the posterior segment are sclera, Brunch's membrane-choroid, retinal pigment epithelium, and conjunctiva. The blood-ocular barrier consists of blood-aqueous barrier and blood-retinal barrier which limits the availability of therapeutic molecules in ocular compartments [12]. 


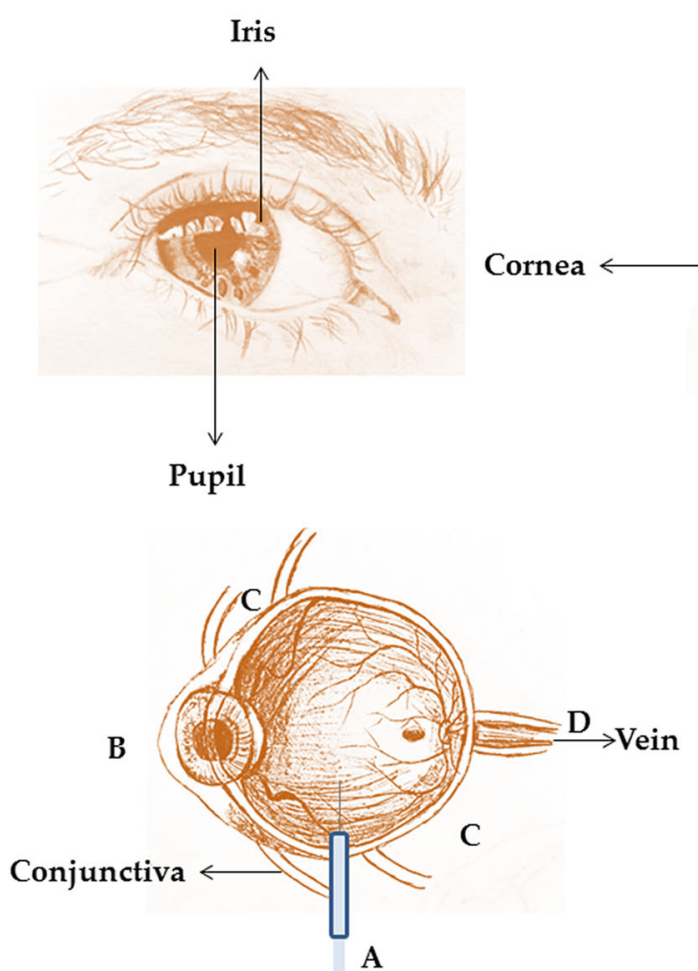

A

Fig. 1 Eye structures and routes of drug administration. Structurally, the eye is composed of an internal compartment which consists of the anterior and posterior chambers-the iris, lens, vitreous cavity, retina, ciliary body, the choroid, and intrinsic ocular muscles-and an external compartment-which consists of the conjunctiva,

Blood-ocular barrier functions are maintenance of tissue/fluid composition, generation of aqueous humor, and keeping pathogens out of the eye (also restricts drugs from entering the eye). The barrier is formed by tight junctions at the level of iris-vascular epithelium and nonpigmented ciliary epithelium, where the blood-aqueous barrier is formed, and at the level of the retinal vascular endothelium and retinal pigment epithelium where the blood-retinal barrier is formed [16].

To date, most common ophthalmic drugs are administered topically in the form of eye drops into the corneal surface. However, such drugs suffer from low bioavailability for the natural barriers. Corneal epithelium is the major barrier for penetration and permeation, preventing the crossing of particles smaller than $21 \mathrm{~nm}$ into the intraocular space [17]. Alternative delivery the cornea, the sclera, and the tear film. There are different routes for eye drug administration like a intravitreal injection; $\mathbf{b}$ topical; $\mathbf{c}$ periocular injections; and $\mathbf{d}$ systemic administration

techniques such as IVT or periocular injections have been developed to resolve the low bioavailability of the topical route, but they are invasive with important side effects such as retinal detachment or intravitreal hemorrhage [11], as previously mentioned.

There are three routes for drug delivery to the back of the eye after topical administration: (a) corneal pathway cornea-vitreous-retina, (b) non-corneal pathway conjunctiva-sclera-choroid-retina, and (c) lateral diffusion pathway cornea-anterior chamber-uvea/sclera tissues [18].

\section{NANOMEDICINE FOR EYE DISEASES}

Nanomedicine is the medical application of nanotechnology, which involves the creation 
and use of materials to construct nanoparticles (NPs) with at least one dimension between 1 and $100 \mathrm{~nm}$ [19]. The most commonly used materials in nanomedicine include lipids (liposomes), proteins (albumin NPs), cyclic oligosaccharides (cyclodextrins), synthetic polymers (polymeric micelles, dendrimers, hydrogel), and inorganic compounds (cerium oxide NPs) (Fig. 2) (Table 1) [20-22]. In the context of ophthalmology, NPs are of interest for their ability to increase the solubility of hydrophobic drugs, their capability to provide sustained drug release with reduced toxicity and improved efficacy, their ability to prolong drug retention time and enhancement of drug penetration through ocular barriers, and their proficiency to direct drugs to specific tissues and cells [19]. The different routes of ocular drug administration of NPs include topical, oral/systemic, subconjunctival, subtenon, retrobulbar, intracameral, and IVT [13].
Some challenges in nanotechnology are (a) nanoparticles aggregate inside the tissues after IVT [23], (b) few in vivo studies have been accomplished, and (c) most ocular pharmacokinetics studies have been performed in animal models, mostly in rabbits. However, the rabbit eye is different from the human eye, and such differences can contribute to the outcomes of IVT drug delivery [27]. Part of the effort to improve nanoparticle therapies focuses on the difficulties described above.

\section{Nanomedicine Based on Liposomes}

Delivery of drugs at therapeutic concentrations to the posterior segment of the ocular chamber (retina/choroid) is a very challenging task [28]. Liposomes constitute a promising nanosystem strategy for ocular drug delivery. Liposomes are the first nano drug delivery systems that have

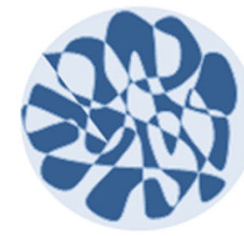

Hydrogel

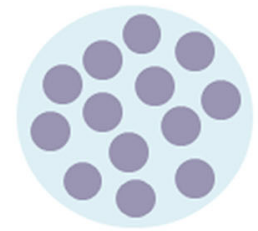

Nanospheres

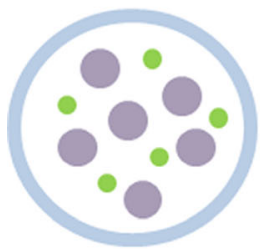

Nanocapsule

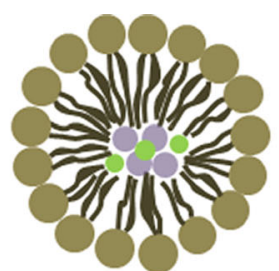

Nanomicelles

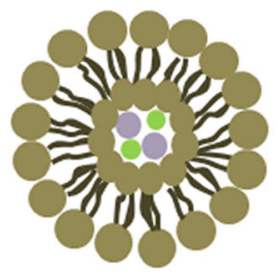

Liposome

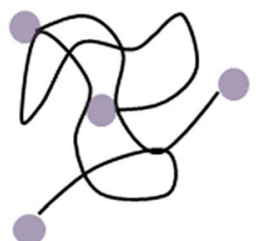

Linear polymers

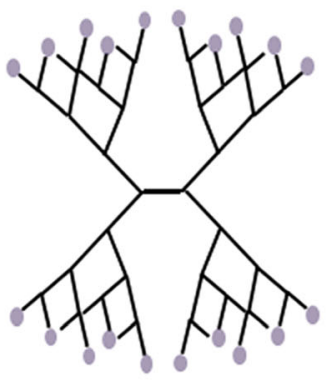

Dendrimers

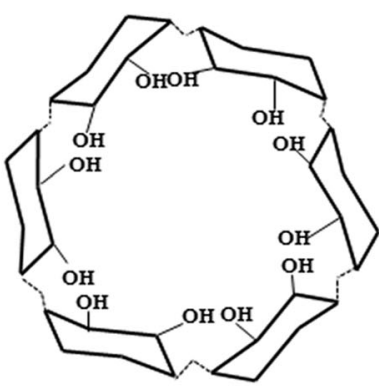

Cyclodextrins

Fig. 2 Materials in nanomedicine for eye drug delivery. Specific nanomolecules have been developed and/or applied as carriers for eye drug delivery. Representative structures of the principal nanoparticles are presented in this figure 
Table 1 Description of the principal materials in nanomedicine for eye drug delivery

\begin{tabular}{|c|c|c|}
\hline Nanoparticle & Description/characteristics & References \\
\hline ydrogels & $\begin{array}{l}\text { Cross-linked polymeric networks with the ability to swell in water or organic solvents. } \\
\text { Depending on the source, hydrogel could be a homopolymer, copolymer, or multiblock. } \\
\text { Copolymerization involves the mixing of monomers with cross-linking agents. } \\
\text { Polymerization products could be powder or microspheres. Hydrogels are biocompatible, } \\
\text { nontoxic, and biodegradable. Another advantage is that stimuli-responsive materials such as } \\
\text { pH- and temperature-sensitive smart hydrogels offer site-specific targeted drug delivery } \\
\text { applications }\end{array}$ & [22] \\
\hline Nanospheres & Are easily made with biodegradable polymers for sustained drug release & [23] \\
\hline Nanocapsules & $\begin{array}{l}\text { Structures that can encapsulate relatively large amounts of drugs and nucleic acids such as } \\
\text { DNA, microRNA, siRNA, and shRNA }\end{array}$ & [23] \\
\hline Nanomicelles & $\begin{array}{l}\text { Generated by the dispersion of amphiphilic molecules, consisting of hydrophobic and } \\
\text { hydrophilic components in solution. Micelles are formed through self-assembly. They have } \\
\text { relatively high stability, minimal cytotoxicity, and suitability for controlled and sustained } \\
\text { drug delivery. Hydrophobic drugs may be incorporated into the cores of micelles. Polymeric } \\
\text { micelles favor targeted therapy and sustained drug delivery owing to the high drug loading } \\
\text { capacity of the inner core. Some are stimuli-sensitive where a drug is released under internal } \\
\text { stimuli like pH or external stimuli like light or temperature }\end{array}$ & {$[22]$} \\
\hline Liposomes & $\begin{array}{l}\text { Small, spherical amphipathic vesicles composed of phospholipids. Biocompatibility, } \\
\text { biodegradability, low toxicity, and site-specific delivery of both hydrophilic and } \\
\text { hydrophobic drugs are some of their advantages. Can encapsulate both hydrophilic and } \\
\text { hydrophobic drugs }\end{array}$ & {$[22]$} \\
\hline $\begin{array}{l}\text { Linear } \\
\text { polymers }\end{array}$ & Polymers to which drug molecules are covalently conjugated & [23] \\
\hline Dendrimers & $\begin{array}{l}\text { Compact structures with tree-like branches or arms. These structures consist of a central core } \\
\text { of an atom or group of atoms from which branches of other atoms grow through a series of } \\
\text { chemical reactions. Dendrimers have sizes in nanometer range and can very easily be } \\
\text { prepared and functionalized. Their application lies in their ability to perform controlled } \\
\text { and targeted drug delivery. Drugs conjugated with dendrimers increased there stability, half- } \\
\text { life, and bioavailability without altering their properties }\end{array}$ & {$[22,24,25]$} \\
\hline Cyclodextrins & $\begin{array}{l}\text { Family of cyclic oligosaccharides, composed of six to eight glucose units which improve } \\
\text { pharmacokinetic properties of drugs through the formation of an inclusion complex. } \\
\text { Cyclodextrins function as permeation enhancers by adhering around the eye surface and } \\
\text { sustaining the drug release }\end{array}$ & {$[11,26]$} \\
\hline
\end{tabular}

$s i R N A$ small interfering RNA, shRNA short hairpin RNA

been successfully translated into real-time clinical applications. Liposomes are spherical vesicles characterized by a bilayer of lipids with an internal aqueous cavity. Liposome structural components are phospholipids or synthetic amphiphiles incorporated with sterols, such as cholesterol, to influence membrane permeability. Thin-film hydration is the most widely used 
preparation method for liposomes, in which lipid components with or without a drug are dissolved in an organic solvent [29]. Besides, liposomes are nontoxic, metabolized, biodegradable, and have low antigenicity [30]. These characteristics make them suitable carriers of several molecules, including drugs.

It is noteworthy that an increasing number of studies have demonstrated longer retention time of drugs loaded in liposomes compared with the free drug administration, thereby reducing the number of IVT injections and their concomitant risks [7, 31-35]. Recently topical liposomal formulations have even been developed to avoid IVT and injection and their hazards.

For example a topical ophthalmic triamcinolone acetonide-liposome formulation (TALF) was developed by our group to accomplish a safer alternative for IVT corticosteroid injection. This TA-LF was used to successfully deliver TA into vitreous and retina of rabbits [36] and its activity was confirmed in patients with refractory macular edema. Twelve eyes with refractory pseudophakic cystoid macular edema (PCME) were treated with TA-LF for 90 days, and patients under treatment showed a significant improvement in visual acuity and in central foveal thickness with no adverse events recorded [37]. Moreover, TA-LF showed its utility to prevent PCME and significantly improve the contrast sensitivity after femtosecond-laserassisted cataract surgery [37, 38].

Chemical modifications to the liposomes are currently being made and evaluated to make the delivery of the drug to the posterior segment of the eye more efficient. Recently Khalil et al. [39] coated liposomes with chitosan with the goal to improve the encapsulation efficiency, retention time, and permeability for a topical formulation of TA. Highlights of their results are that this liposome modification enhances encapsulation efficiency, increases retention time, and sustained release when compared with the conventional liposome loaded with TA. The chitosan-coated liposomes showed successful in vivo penetration of the corneal mucosal barrier and accumulation in vitreous body after topical administration, coinciding with what was previously reported by Li et al. [40]. Regardless of all this information, our recently published data demonstrates the only evidence of successful use in a clinical scenario [37].

More complex systems have been created like the nanosystem of $\mathrm{Gu}$ et al. [18], who designed novel multifunctional nanocomposites for efficient drug delivery to the posterior segment via topical instillation. Their system was generated by hybridizing dexamethasone salt-loaded liposome with glycylsarcosine-anchored layered double hydroxide, the latter as a positive carrier that promoted precorneal retention via electrostatic adsorption. The system showed sustained-release performance and prolonged precorneal retention. In vivo eye distribution assay of the nanosystem showed strong residence on the eye surface compared with commercial eye drops. Two hours after topical administration the drug concentration remained in the choroidal and retinal tissues at therapeutic concentrations, even higher, indicating that this nanosystem could effectively deliver the drug to the posterior segment of the eye.

Liposomes became the first nanomedicines in US Food and Drug Administration (FDA) clinical trials [41]. Interventional clinical trials are summarized in Table 2 according to status (recruiting; enrolling by invitation; active, not recruiting; or completed) [37, 38, 42].

\section{Nanomedicine Based on Other Nanoparticles}

Other types of lipids have been used for eye drug delivery. Solid lipid nanoparticles (SLN) are being developed to overcome disadvantages of other colloidal carriers like liposomes. Lipid components of SLN are solid at body and ambient temperature. SLN are composed of $0.1-30 \%(\mathrm{w} / \mathrm{w})$ solid fat which is dispersed in an aqueous phase. The lipids used in SLN include fatty acids, steroids, waxes, monoglycerides, diglycerides, and triglycerides. Compared with liposomes, SLN have drug stability and prolonged release and they are safer because no organic solvents are used in their production; others benefits are easy preparation, low cost, 
Table 2 Clinical trials of liposomes for treatment of eye diseases

\begin{tabular}{|c|c|c|c|c|c|}
\hline Status & Title & $\begin{array}{l}\text { Study } \\
\text { phase }\end{array}$ & Intervention & Country & Identifier \\
\hline Completed & $\begin{array}{l}\text { Cross-linked hyaluronic acid } \\
\text { with liposomes and crocin } \\
\text { in the treatment of dry } \\
\text { eye disease due to } \\
\text { moderate meibomian } \\
\text { gland dysfunction }\end{array}$ & $\begin{array}{l}\text { Not } \\
\text { applicable }\end{array}$ & $\begin{array}{l}\text { One drop application of } \\
\text { cross-linked hylauronic } \\
\text { acid }+ \text { liposomes with a } \\
\text { dosage of } 3 \text { times a day for } \\
45 \text { days }\end{array}$ & Spain & NCT03617315 \\
\hline Completed & $\begin{array}{l}\text { Safety and efficacy of } \\
\text { liposomal latanoprost in } \\
\text { ocular hypertensive } \\
\text { patients }\end{array}$ & $\mathrm{I} / \mathrm{II}$ & $\begin{array}{l}\text { Subconjunctival injection of } \\
\text { liposomal latanoprost }\end{array}$ & Singapore & NCT01987323 \\
\hline Recruiting & $\begin{array}{l}\text { Effectiveness of liposomal } \\
\text { ozonized oil on ocular } \\
\text { microbial flora before } \\
\text { cataract surgery }\end{array}$ & IV & $\begin{array}{l}\text { OZODROP }^{\circledR} \text { (ozonized oil } \\
0.5 \% \text { in liposomes) } \\
\text { ophthalmic solution, } 2 \\
\text { drops } 4 \text { times a day. } \\
\text { OZODROP }{ }^{\circledR} \text { will be } \\
\text { instilled in the eye that } \\
\text { will have to undergo } \\
\text { cataract surgery }\end{array}$ & Italy & NCT04087733 \\
\hline Completed & $\begin{array}{l}\text { An open study to assess the } \\
\text { safety and patients } \\
\text { satisfaction Tears Again } \\
\text { in the treatment of dry } \\
\text { eye symptoms }\end{array}$ & $\begin{array}{l}\text { Not } \\
\text { applicable }\end{array}$ & Liposome eye spray & Israel & NCT00535054 \\
\hline Completed & $\begin{array}{l}\text { An open-label comparison } \\
\text { of the safety and efficacy } \\
\text { of subconjunctival } \\
\text { liposomal latanoprost } \\
\text { (POLAT-001) to } \\
\text { latanoprost ophthalmic } \\
\text { solution in patients with } \\
\text { ocular hypertension and } \\
\text { primary open angle } \\
\text { glaucoma }\end{array}$ & II & $\begin{array}{l}\text { Latanoprost liposome } \\
\text { ophthalmic injection }\end{array}$ & USA & NCT02466399 \\
\hline Recruiting & $\begin{array}{l}\text { Phase I/II trial of TLC399 } \\
\text { (ProDex) in patients with } \\
\text { macular edema due to } \\
\text { retinal vein occlusion } \\
\text { (RVO) }\end{array}$ & $\mathrm{I} / \mathrm{II}$ & TLC399. Lipid formulation & Taiwan & NCT02006147 \\
\hline
\end{tabular}


Table 2 continued

\begin{tabular}{|c|c|c|c|c|c|}
\hline$\overline{\text { Status }}$ & Title & $\begin{array}{l}\text { Study } \\
\text { phase }\end{array}$ & Intervention & Country & Identifier \\
\hline $\begin{array}{l}\text { Active, not } \\
\text { recruiting }\end{array}$ & $\begin{array}{l}\text { TLC399 (ProDex) in } \\
\text { subjects with macular } \\
\text { edema due to retinal vein } \\
\text { occlusion (RVO) }\end{array}$ & II & TLC399. Lipid formulation & USA & NCT03093701 \\
\hline Completed & $\begin{array}{l}\text { Evaluation of topical } \\
\text { ophthalmic liposomes } \\
\text { formulation carrying } \\
\text { triamcinolone acetonide } \\
0.1-0.2 \%\end{array}$ & II & $\begin{array}{l}\text { Topical triamcinolone } \\
\text { acetonide-loaded } \\
\text { liposomes to treat } \\
\text { posterior segment } \\
\text { disorders }\end{array}$ & Mexico & $\begin{array}{l}\text { COFEPRIS } \\
173300410 \mathrm{~A} 0035 / \\
2017\end{array}$ \\
\hline Recruiting & $\begin{array}{l}\text { OCS- } 01 \text { in treating } \\
\text { inflammation and pain in } \\
\text { post-cataract patients }\end{array}$ & II & $\begin{array}{l}\text { OCS-01-dexamethasone } \\
\text { cyclodextrin nanoparticle } \\
\text { ophthalmic suspension } \\
1.5 \% \mathrm{mg} / \mathrm{mL}\end{array}$ & USA & NCT04130802 \\
\hline
\end{tabular}

high-scale production, chemical versatility, among others [43]. Promising results have been achieved with the use of SLN as a nanosystem eye drug delivery. Abrishami et al. [44] administered SLN containing diclofenac into eyes of rabbits via IVT injection; comparing with the free drug form, the drug concentration in eyes injected with SLN was significantly higher than the eyes treated with the free form, a characteristic allowing one to increase the injection intervals and improve the patient compliance. On the other hand, Singh et al. [45] delivered isoniazid in SLN; isoniazid is a potential bactericidal agent used to treat all forms of tuberculosis. The in vivo aqueous humor pharmacokinetics showed an isoniazid-SLN extended release, enhanced corneal permeability, increased ocular bioavailability, among other characteristics.

Other types of NPs have been provided. Kashiwagi et al. [46] fabricated a multilayered biodegradable nanosheet composed of chitosan and sodium alginate and latanoprost (antiglaucoma ophthalmic drug) loaded on the nanosheet to reduce intraocular pressure. The nanosheet was applied into the center of the cornea of Sprague-Dawley rats. After nanosystem administration intraocular pressure was monitored until 9 days after. The authors observed a significant intraocular pressure reduction after treatment with no local adverse effects. Using the same approach, Wang et al. [47] combined two drugs (latanoprost and timolol) in a nanosheet made of alginate and chitosan to reduce intraocular pressure in a slow and sustained manner for possible therapeutic strategy in glaucoma disease. In an in vivo study, the administration of the nanosheet reduced intraocular pressure 9 days after application. These results concurred with those of Kashiwagi et al. [46].

For the first time Silva et al. [48] designed a new erythropoietin formula for topical ocular administration. They developed a mucoadhesive hydrogel of chitosan and hyaluronic acid as a nanosystem for topical delivery. The ex vivo permeation evaluation using conjunctivas, corneas, and scleras from pig eyes showed that the nanosystem formulation permeated more rapidly through the conjunctiva, followed by 
the sclera and the cornea. Thus, this carrier form could increase erythropoietin ocular bioavailability through the enhanced retention time and permeation in the different ocular membranes. Hamcerencu et al. [49] generated a thermoreversible hydrogel as ocular insert using gellan maleate and $\mathrm{N}$-isopropylacrylamide (alkyl acrylamide). The resultant hydrogel showed a temperature-responsive behavior, releasing the biological active compound (adrenaline) when the polymer conformation changes. Animals included in the in vivo biocompatibility test showed good tolerance to the implanted hydrogel. With the in vivo release assay, the authors found no changes in anatomical structures after $24 \mathrm{~h}$ and the effect of the drug was demonstrated after 60-90 s, suggesting efficiency of the inserts without complications.

On the other hand, polymeric micelles are core/shell-structured NPs formed by self-assembly. The core/shell structure enables encapsulation of hydrophobic drugs [11]. In 2017 Mandal et al. [50] published a review about the techni$\mathrm{cal} / \mathrm{chemical}$ aspects and preclinical studies of the polymeric micelles in the field of ocular drug delivery. Recently $\mathrm{Xu}$ et al. [51] used nanomicelles of chitosan for topical eye delivery of dexamethasone. Nanomicelles were prepared with chitosan oligosaccharide-valyvaline-stearic acid, in which valyvaline functioned as a targeting ligand of eye peptide transporter 1 . The in vivo ocular assays exhibited sustained release, biocompatibility, bioavailability, good retention time, and penetration-enhancing properties. In similar way, $\mathrm{Yu}$ et al. [52] utilized chitosan nanomicelles to carry dexamethasone with similar achieved results, suggesting that selfassembled chitosan nanoparticles might be a promising candidate for ophthalmic drug delivery.

In another study, Sai et al. [53] formulated an in situ gel-forming system with micelles incorporated for curcumin eye delivery. The system was based on 1,2-distearoyl-sn-glycero-3-phosphoethanolamine- $N$-[methoxy(polyethylene glycol)-2000] (PEG-DSPE)/polyoxyethylene esters of 12-hydroxystearic acid (Solutol HS 15) (PEG-DSPE/Solutol HS 15) mixed micelles and gellan gum. This approach significantly increased the solubility of curcumin. In vivo assays showed that the nanosystem increased the eye retention time of curcumin, possibly owing to the formation of a gel network under the influence of cations from tears.

Novel nanocarriers have been proven, e.g., the sweetener constituent of Stevia rebaudiana, rebaudioside A (RA). The chemical structure of RA allows one to generate ultrasmall micelles in aqueous solution [54]; on the basis of that characteristic, Song et al. [55] encapsulated pterostilbene, a natural antioxidant, in selfassembled ultrasmall micelles of RA. The authors administered RA-pterostilbene into the eyes of different animals (rabbit, mouse, rats); the results showed a significant improvement of intraocular permeation of RA-pterostilbene, compared with the free drug, and in consequence enhanced efficacy of the drug. Another natural molecule is ginsenoside Rb1 (Rb1), a principal bioactive molecule in the roots of Panax ginseng with intrinsic functions including antioxidative, anti-inflammatory, anti-angiogenic, and neuroprotective effects. In addition, the chemical structure of Rb1 has a hydrophobic side chain and a hydrophilic sugar side chain which allow formation of self-assembled micelles in aqueous solutions [56]. Li et al. [56] formulated diclofenac-loaded $\mathrm{Rb} 1$ micelles. Animal permeation tests showed increased concentrations of diclofenac in corneas of rabbits administered with Rb1 nanomicelles compared with commercial diclofenac eye drops, but the concentration in the aqueous humor was undetectable, the formulation showed no additional viscosity above that of water, and drained away from the eye surface.

A different novel approach was developed by Göttel et al. [57] in which a drug delivery system is applied in dry form and forms a gel immediately after administration. The system innovation is based on gellan gum/pullulan electrospun nanofibers. After dye-loaded fibers were sprayed onto porcine corneas, the fibers showed a homogeneous distribution over the cornea surface and a prolonged residence time compared to conventional eye drops. To ensure a good fit to the eye anatomy, the authors 
prepared fibers shaped into curved geometries for future applications.

Wang et al. [58] designed a system in which NPs are injected intravenously and are converted to a tissue-targeting state only upon irradiation in the eye. The general design was based in photo-targeted NPs that are formed by self-assembly of a chemically modified poly(ethylene oxide)-poly(D,L-lactic acid) (PEG-PLA) block copolymer; this core presents other surface elements including the "peptide cargo" and a targeting molecule that allows local drug delivery and in situ activation upon irradiation with blue light. The NPs were intravenously administered in mice with laser-induced choroidal neovascularization. Immediately after injection, NPs were observed in the mouse fundus in the retinal blood vessels, visible in vivo after $8 \mathrm{~h}$ after administration. After the proof of concept, to evaluate the therapeutic effect of the phototriggered activation of NPs in choroidal neovascularization, the authors loaded NPs with doxorubicin which inhibits choroidal neovascularization. NPs were injected via tail vein and $30 \mathrm{~s}$ thereafter, the mouse eyes were irradiated with blue light. Animals treated with NPs loaded with doxorubicin showed a $46.1 \%$ reduction in neovessel area compared to the control group.

Liu et al. [26] modified $\beta$-cyclodextrin with ethylene diamine as a nanocarrier of curcumin for eye delivery. In vitro assays of the modified $\beta$-cyclodextrin displayed enhanced corneal penetration with improved biocompatibility. Ethylene diamine- $\beta$-cyclodextrin encapsulation could hugely promote corneal curcumin delivery. On the other hand, Mazet et al. [59] explored the effect of mixing dexamethasone with cyclodextrin to improve the aqueous solubility of curcumin. Hydroxypropyl- $\beta$-cyclodextrins and hydroxypropyl- $\gamma$-cyclodextrins were combined with a marketed mucoadhesive gel for topical administration. The in vitro studies showed that the inclusion of hydroxypropyl- $\gamma$-cyclodextrin increased 1500 -fold the drug concentration in a water solution and an appropriate release factor. Lorenzo-Veiga et al. [25] improved the cyclodextrin characteristics by mixing it with different hydrophilic polymers to generate nanoaggreagtes with nepafenac (potent non-steroidal anti-inflammatory drug) and to promote solubility. In contrast with Mazet et al., the best results of solubility were accomplished with the use of hydroxypropyl- $\beta$-cyclodextrin, for this particular drug, while hydroxypropyl- $\gamma$-cyclodextrin performed best in terms of enhancing nanoaggregate formation. They observed that addition of hydrophilic polymers carboxymethylcellulose, polyvinylpyrrolidone, and tyloxapol to the formulation with cyclodextrins led to higher nepafenac solubility.

Jóhannesson et al. [60] hypothesized that high concentration of drug in eye drops and adhesion of nanoparticles to the mucous membrane enhances the drug bioavailability in the tear film. To prove their hypothesis, they evaluated the concentration of nanoparticles of dexamethasone $\gamma$-cyclodextrin and dorzolamide $\gamma$-cyclodextrin in the tear film of human volunteers. Twelve volunteers were randomized in two groups, six eyes received one drop of dexamethasone $\gamma$-cyclodextrin and the control eyes the regular dexamethasone. Tear fluid was sampled at seven points after treatment administration and the drug concentration was measured by mass spectrometry. The same was performed for the dorzolamide $\gamma$-cyclodextrin. The results showed that dexamethasone $\gamma$-cyclodextrin nanoparticles had higher concentration and with longer duration in tear fluid than the regular dexamethasone; the effect was not replicated with dorzolamide $\gamma$-cyclodextrin, which may be explained by the particle sizes achieved for each drop of preparation: some of the particles of the dexamethasone $\gamma$-cyclodextrin had nanoparticle diameters of $100 \mathrm{~nm}$, whereas dorzolamide $\gamma$-cyclodextrin had microparticles with particle sizes higher than $100 \mathrm{~nm}$ that could have modified the drug kinetics.

Ohira et al. [61] described the results of a prospective randomized controlled trial in which 22 patients were included with diabetic macular edema and randomized in two arms: (a) topical treatment with dexamethasone $\gamma$ cyclodextrin nanoparticle eye drops or (b) one posterior subtenon injection of triamcinolone acetonide. The patients were followed for 16 weeks. The treatment with dexamethasone 
$\gamma$-cyclodextrin nanoparticle eye drops significantly improved vision and macular thickness. The therapeutic outcome was similar to that achieved with subtenon triamcinolone injections. The clinical trial outcomes showed that this dexamethasone $\gamma$-cyclodextrin nanoparticle eye drop (topical administration) had a significant effect in the posterior segment of the ocular globe comparable with invasive techniques.

\section{CONCLUSIONS}

Visual impairment is a health problem around the world. Topical application of eye drops is still the most common therapeutic route for treatment of eye diseases. Important improvement has been achieved at the preclinical level using nanoparticles as carriers for eye drug delivery. Nevertheless, it is necessary to translate these findings to clinical scenarios by designing controlled clinical trials.

\section{ACKNOWLEDGEMENTS}

Funding. No funding or sponsorship was received for this review or publication of this article.

Authorship. All named authors meet the International Committee of Medical Journal Editors (ICMJE) criteria for authorship for this article, take responsibility for the integrity of the work as a whole, and have given their approval for this version to be published.

Disclosures. Alejandra Meza-Rios, Jose Navarro-Partida, Juan Armendariz-Borunda, and Arturo Santos-Garcia declare that they have no conflict of interest.

Compliance with Ethics Guidelines. This article is based on previously conducted studies and does not contain any studies with human participants or animals performed by any of the authors.
Data Availability. Data sharing is not applicable to this article as no datasets were generated or analyzed during the current study.

Open Access. This article is licensed under a Creative Commons Attribution-NonCommercial 4.0 International License, which permits any non-commercial use, sharing, adaptation, distribution and reproduction in any medium or format, as long as you give appropriate credit to the original author(s) and the source, provide a link to the Creative Commons licence, and indicate if changes were made. The images or other third party material in this article are included in the article's Creative Commons licence, unless indicated otherwise in a credit line to the material. If material is not included in the article's Creative Commons licence and your intended use is not permitted by statutory regulation or exceeds the permitted use, you will need to obtain permission directly from the copyright holder. To view a copy of this licence, visit http:// creativecommons.org/licenses/by-nc/4.0/.

\section{REFERENCES}

1. Pascolini D, Mariotti SP. Global estimates of visual impairment: 2010. Br J Ophthalmol. 2012;96: $614-8$.

2. Flaxman SR, Bourne RRA, Resnikoff S, et al. Global causes of blindness and distance vision impairment 1990-2020: a systematic review and meta-analysis. Lancet Glob Health. 2017;5:e1221-e12341234.

3. Yau JW, Rogers SL, Kawasaki R, et al. Global prevalence and major risk factors of diabetic retinopathy. Diabetes Care. 2012;35:556-64.

4. Tan GS, Cheung N, Simó R, Cheung GC, Wong TY. Diabetic macular oedema. Lancet Diabetes Endocrinol. 2017;5:143-55.

5. Grzybowski A, Told R, Sacu S, et al. 2018 Update on intravitreal injections: euretina expert consensus recommendations. Ophthalmologica. 2018;239: 181-93.

6. Lai S, Wei Y, Wu Q, et al. Liposomes for effective drug delivery to the ocular posterior chamber. J Nanobiotechnol. 2019;17:64. 
7. Blazaki S, Pachis K, Tzatzarakis M, Tsilimbaris M, Antimisiaris SG. Novel liposome aggregate platform (LPA) system for sustained retention of drugs in the posterior ocular segment following intravitreal injection. Int J Pharm. 2019;576:118987.

8. Petri AS, Boysen K, Cehofski LJ, et al. Intravitreal Injections with vascular endothelial growth factor inhibitors: a practical approach. Ophthalmol Ther. 2020;9:191-203.

9. Azad R, Chandra P, Gupta R. The economic implications of the use of anti-vascular endothelial growth factor drugs in age-related macular degeneration. Indian J ophthalmol. 2007;55:441.

10. Subhi Y, Sorensen TL. Neovascular age-related macular degeneration in the very old ( $\geq 90$ years): epidemiology, adherence to treatment, and comparison of efficacy. J Ophthalmol. 2017;2017: 7194927.

11. Liu S, Jones L, Gu FX. Nanomaterials for ocular drug delivery. Macromol Biosci. 2012;12:608-20.

12. Agrahari V, Mandal A, Agrahari V, et al. A comprehensive insight on ocular pharmacokinetics. Drug Deliv Transl Res. 2016;6:735-54.

13. Santos A, Altamirano JC, Navarro-Partida J, González-De la Rosa A, Hsiao JH. Breaking down the barrier: topical liposomes as nanocarriers for drug delivery into the posterior segment of the eyeball. In: Tayagi RV, Garg N, Shukla R, Singh Bisen P, editors. Role of novel drug delivery vehicles in nanobiomedicine. IntechOpen; 2019. https://doi. org/10.5772/intechopen.86601.

14. Holmes D. Reconstructing the retina. Nature. 2018;561:S2-S3.

15. Frank RN, Glybina I. Macular oedema. In: Dartt D, Besharse JC, Dana MR, editors. Encyclopedia of the eye, vol. 3. Oxford: Elsevier; 2010. p. 1-12.

16. Moisseiev E, Loewenstein A. Drug delivery to the posterior segment of the eye. In: Coscas $G$, editor. Macular edema, vol. 58, 2nd edn. Dev Ophthalmol. Basel, Karger; 2017. p. 87-101

17. Weng Y, Liu J, Jin S, Guo W, Liang X, Hu Z. Nanotechnology-based strategies for treatment of ocular disease. Acta Pharm Sin B. 2017;7:281-91.

18. Gu Y, Xu C, Wang Y, Zhou X, Fang L, Cao F. Multifunctional nanocomposites based on liposomes and layered double hydroxides conjugated with glycylsarcosine for efficient topical drug delivery to the posterior segment of the eye. Mol Pharm. 2019;16:2845-57.
19. Kamaleddin MA. Nano-ophthalmology: applications and considerations. Nanmedicine. 2017;13(4):1459-72.

20. Mukherjee A, Waters AK, Kalyan P, Achrol AS, Kesari S, Yenugonda VM. Lipid-polymer hybrid nanoparticles as a next-generation drug delivery platform: state of the art, emerging technologies, and perspectives. Int J Nanomedicine. 2019;14: 1937-52.

21. Souto EB, Dias-Ferreira J, López-Machado A, et al. Advanced formulation approaches for ocular drug delivery: state-of-the-art and recent patents. Pharmaceutics. 2019;11:E460.

22. Singh AP, Biswas A, Shukla A, Maiti P. Targeted therapy in chronic diseases using nanomaterialsbased drug delivery vehicles. Signal Transduct Target Ther. 2019;4:33.

23. $\mathrm{Xu} \mathrm{Q}$, Kambhampati SP, Kannan RM. Nanotechnology approaches for ocular drug delivery. Middle East Afr J Ophthalmol. 2013;20(1):26-37.

24. Bhattacharjee A, Das PJ, Adhikari P, et al. Novel drug delivery systems for ocular therapy: with special references to liposomal ocular delivery. Eur J Ophthalmol. 2019;29(1):113-26.

25. Lorenzo-Veiga B, Sigurdsson HH, Loftsson $\mathrm{T}$. Nepafenac-loaded cyclodextrin/polymer nanoaggregates: a new approach to eye drop formulation. Materials (Basel). 2019;12:E229.

26. Liu CH, Lee GW, Wu WC, Wang CC. Encapsulating curcumin in ethylene diamine- $\beta$-cyclodextrin nanoparticle improves topical cornea delivery. Colloids Surf B Biointerfaces. 2019;186:110726.

27. Rowe-Rendleman CL, Durazo SA, Kompella UB, et al. Drug and gene delivery to the back of the eye: from bench to bedside. Investig Ophthalmol Vis Sci. 2014;55:2714-30.

28. Trinh HM, Cholkar K, Joseph M, Yang X, Mitra AK. Clear, aqueous topical drop of triamcinolone acetonide. AAPS PharmaSciTech. 2017;18(7):2466-78.

29. Bulbake U, Doppalapudi S, Kommineni N, Khan W. Liposomal formulations in clinical use: an updated review. Pharmaceutics. 2017;9(2):E12.

30. van Rooijen N, van Nieuwmegen R. Liposomes in immunology: multilamellar phosphatidylcholine liposomes as a simple, biodegradable and harmless adjuvant without any immunogenic activity of its own. Immunol Commun. 1980;9:243-56.

31. Gupta SK, Velpandian T, Dhingra N, Jaiswal J. Intravitreal pharmacokinetics of plain and 
liposome-entrapped fluconazole in rabbit eyes. J Ocul Pharmacol Ther. 2000;16(6):511-8.

32. Zhang R, He R, Qian JA, Guo J, Xue K, Yuan YF. Treatment of experimental autoimmune uveoretinitis with intravitreal injection of tacrolimus (FK506) encapsulated in liposomes. Investig Ophthalmol Vis Sci. 2010;51:3575-82.

33. Cannon JP, Fiscella R, Pattharachayakul S, et al. Comparative toxicity and concentrations of intravitreal amphotericin B formulations in a rabbit model. Investig Ophthalmol Vis Sci. 2003;44: 2112-7.

34. Claro C, Ruiz R, Cordero E, et al. Determination and pharmacokinetic profile of liposomal foscarnet in rabbit ocular tissues after intravitreal administration. Exp Eye Res. 2009;88:528-34.

35. Zeng $\mathrm{S}, \mathrm{Hu} \mathrm{C}$, Wei $\mathrm{H}$, et al. Intravitreal pharmacokinetics of liposome-encapsulated amikacin in a rabbit model. Ophthalmology. 1993;100:1640-4.

36. Altamirano-Vallejo JC, Navarro-Partida J, GonzalezDe la Rosa A, et al. Characterization and pharmacokinetics of triamcinolone acetonide-loaded liposomes topical formulations for vitreoretinal drug delivery. J Ocul Pharmacol Ther. 2018;34:416-25.

37. Gonzalez-De la Rosa A, Navarro-Partida J, Altamirano-Vallejo JC, et al. Novel triamcinolone acetonide-loaded liposomes topical formulation for the treatment of cystoid macular edema after cataract surgery: a pilot study. J Ocul Pharmacol Ther. 2019;35:106-15.

38. Gonzalez-De la Rosa A, Navarro-Partida J, Altamirano-Vallejo JC, et al. Novel triamcinolone acetonide-loaded liposomes topical formulation improves contrast sensitivity outcome after femtosecond laser-assisted cataract surgery. J Ocul Pharmacol Ther. 2019;35:512-21.

39. Khalil M, Hashmi U, Riaz R, Rukh AS. Chitosan coated liposomes (CCL) containing triamcinolone acetonide for sustained delivery: a potential topical treatment for posterior segment diseases. Int J Biol Macromol. 2020;143:483-91.

40. Li J, Cheng T, Tian Q, et al. A more efficient ocular delivery system of triamcinolone acetonide as eye drop to the posterior segment of the eye. Drug Deliv. 2019;26:188-98.

41. Bobo D, Robinson KJ, Islam J, Thurecht KJ, Corrie SR. Nanoparticle-based medicines: a review of FDAapproved materials and clinical trials to date. Pharm Res. 2016;33:2373-87.

42. Clinicaltrials.gov. https://clinicaltrials.gov/. Accessed 20 Apr 2020.
43. Naseri N, Valizadeh H, Zakeri-Milani P. Solid lipid nanoparticles and nanostructured lipid carriers: structure preparation and application. Adv Pharm Bull. 2015;5:305-13.

44. Abrishami M, Abrishami M, Mahmoudi A, Mosallaei N, Vakili ARM, Malaekeh-Nikouei B. Solid lipid nanoparticles improve the diclofenac availability in vitreous after intraocular injection. J Drug Deliv. 2016;2016:1368481.

45. Singh M, Guzman-Aranguez A, Hussain A, Srinivas CS, Kaur IP. Solid lipid nanoparticles for ocular delivery of isoniazid: evaluation, proof of concept and in vivo safety \& kinetics. Nanomedicine (Lond). 2019;14:465-91.

46. Kashiwagi K, Ito K, Haniuda H, Ohtsubo S, Takeoka S. Development of latanoprost-loaded biodegradable nanosheet as a new drug delivery system for glaucoma. Investig Ophthalmol Vis Sci. 2013;54: 5629-37.

47. Wang L, Jiang YY, Lin N. Promise of latanoprost and timolol loaded combinatorial nanosheet for therapeutic applications in glaucoma. J King Saud Univ Sci. 2020;32:1042-7.

48. Silva B, Marto J, Braz BS, Delgado E, Almeida AJ, Goncalves L. New nanoparticles for topical ocular delivery of erythropoietin. Int J Pharm. 2020;576: 119020 .

49. Hamcerencu M, Desbrieres J, Popa M. Thermosensitive gellan maleate/ $N$-isopropylacrylamide hydrogels: initial "in vitro" and "in vivo" evaluation as ocular inserts. Polym Bull. 2020;77:741.

50. Mandal A, Bisht R, Rupenthal ID, Mitra AK. Polymeric micelles for ocular drug delivery: from structural frameworks to recent preclinical studies. J Control Release. 2017;248:96-116.

51. Xu X, Sun L, Zhou L, Cheng Y, Cao F. Functional chitosan oligosaccharide nanomicelles for topical ocular drug delivery of dexamethasone. Carbohydr Polym. 2020;227:115356.

52. Yu A, Shi H, Liu H, et al. Mucoadhesive dexamethasone-glycol chitosan nanoparticles for ophthalmic drug delivery. Int J Pharm. 2020;575: 118943.

53. Sai N, Dong X, Huang P, et al. A novel gel-forming solution based on PEG-DSPE/Solutol HS 15 mixed micelles and gellan gum for ophthalmic delivery of curcumin. Molecules. 2019;25:E81.

54. Song K, Xin M, Yu H. Novel ultra-small micelles based on rebaudioside A: a potential nanoplatform for ocular drug delivery. Int J Pharm. 2018;552: 265-76. 
55. Song K, Xin M, Zhang F, Xie W, Sun M, Wu X. Novel ultrasmall nanomicelles based on rebaudioside A: a potential nanoplatform for the ocular delivery of pterostilbene. Int J Pharm. 2020;577: 119035.

56. Li M, Lan J, Li X, et al. Novel ultra-small micelles based on ginsenoside $\mathrm{Rb} 1$ : a potential nanoplataform for ocular drug delivery. Drug Deliv. 2019;26: 481-9.

57. Göttel B, de Souza e Silva JM, de Oliveira CS, et al. Electrospun nanofibers-a promising solid in situ gelling alternative for ocular drug delivery. Eur J Pharm Biopharm. 2020;146:125-32.

58. Wang Y, Liu CH, Ji T, et al. Intravenous treatment of choroidal neovascularization by photo-targeted nanoparticles. Nat Commun. 2019;10:804.
59. Mazet R, Choisnard L, Levilly D, Wouessidjewe D, Géze A. Investigation of combined cyclodextrin and hydrogel formulation for ocular delivery of dexamethasone acetate by means of experimental designs. Pharmaceutics. 2018;10:E249.

60. Jóhannesson G, Moya-Ortega MD, Ásgrímsdóttir GM, et al. Kinetics of $\gamma$-cyclodextrin nanoparticles suspension eye drops in tear fluid. Acta Ophthalmol. 2014;92:550-6.

61. Ohira A, Hara K, Jóhannesson G, et al. Topical dexamethasone $\gamma$-cyclodextrin nanoparticle eye drop increase visual acuity and decrease macular thickness in diabetic macular oedema. Acto Ophthalmol. 2015;93:610-5. 